\title{
sciendo
}

\section{Dummett's Legacy: Semantics, Metaphysics and Linguistic Competence}

\author{
Massimiliano Vignolo \\ University of Genoa
}

DOI: $10.2478 /$ disp-2015-0011

BIBLID [0873-626X (2015) 41; pp. 207-229]

\begin{abstract}
Throughout his philosophical career, Michael Dummett held firmly two theses: (I) the theory of meaning has a central position in philosophy and all other forms of philosophical inquiry rest upon semantic analysis, in particular semantic issues replace traditional metaphysical issues; (II) the theory of meaning is a theory of understanding. I will defend neither of them. However, I will argue that there is an important lesson we can learn by reflecting on the link between linguistic competence and semantics, which I take to be an important part of Dummett's legacy in philosophy of language. I discuss this point in relation to Cappelen and Lepore's criticism of Incompleteness Arguments.
\end{abstract}

\section{Keywords}

Sematics, pragmatics, metaphysics.

\section{Dummett's legacy: semantics and metaphysics}

Throughout his philosophical career, Michael Dummett never gave up two main theses:

(I) The theory of meaning has a central and foundational place in philosophy.

(II) The theory of meaning is a theory of understanding.

Thesis (I) is the climax of the linguistic turn started with Frege and adopted later by logical positivists. It is the view that metaphysical issues must be resolved, or dissolved, by recourse to the theory of meaning. Contrary to positivists, who dismissed metaphysical issues either as nonsense or as issues concerning no matters of fact and reducible to pragmatic choices between different languages, Dummett

Disputatio, Vol. VII, No. 41, November 2015

Received: 07/01/2015 Revised: 27/07/2015 Accepted: 12/10/2015 
reinterpreted metaphysical disputes as disputes concerning the truth conditions of sentences. ${ }^{1}$ Whether one is justified to be a realist in some area of discourse depends on whether one is justified to assign realist truth conditions to sentences in that area of discourse, i.e. bivalent, epistemically transcendent truth conditions. Linguistic categories are also the starting point for the analysis of formal ontological notions. For example, the formal notion of object is to be understood in terms of the notion of reference of singular terms - with the notion of singular term to be explained on the basis of characteristic behaviour in syntactic and logical operations on sentences containing singular terms. ${ }^{2}$ Dummett gave the philosophy of language a foundational role. If metaphysical issues are reformulated as questions about the structure and content of language, only the philosophy of language can provide the analysis of such structure.

Nowadays many, perhaps most, philosophers reject the foundational role of the philosophy of language and claim a substantive and autonomous role for metaphysics. They regard metaphysics as that part of the philosophical inquiry that is engaged to discover objective characteristics of reality and not the fundamental features of our thought about reality.

Thesis (II) is also central in Dummett's philosophy and struggle against semantic realism. According to Dummett, the theory of meaning must be tripartite in (a) a theory of reference, (b) a theory of sense and (c) a theory of force. ${ }^{3}$ The theory of reference determines recursively the conditions for the application to each sentence of that notion which is understood as the central notion in the explanation

${ }^{1}$ See Dummett 1978: xl: 'The whole point of my approach to these problems [the disputes concerning realism] has been to show that the theory of meaning underlies metaphysics. If I have made any worthwhile contribution to philosophy, I think it must lie in having raised this issue in these terms.'

${ }^{2}$ See Dummett 1981. For a discussion of this point, see Wright 1983:53-64.

${ }^{3}$ See Dummett 1976: 127: 'Any theory of meaning was early seen as falling into three parts: the first, the core theory, the theory of reference; secondly, its shell, the theory of sense; and thirdly, the supplementary part of the theory of meaning, the theory of force... The theory of reference determines recursively the application to each sentence of that notion which is taken as central in the given theory of meaning... The theory of sense specifies what is involved in attributing to a speaker a knowledge of the theory of reference.' 
of meaning. The theory of sense specifies what is involved in ascribing the knowledge of the theory of reference to speakers. The theory of sense is a theory of understanding that specifies that in which the knowledge of the theory of reference consists. ${ }^{4}$ As the knowledge of the theory of reference is an implicit form of knowledge, the theory of sense must correlate the knowledge of each theorem of the theory of reference with a practical linguistic ability. ${ }^{5}$ Dummett's criticism of semantic realism is that the classical notion of truth cannot serve as the central notion in the explanation of meaning, since it makes it impossible to construct a proper theory of sense. This is to say that one cannot specify what is involved in ascribing to speakers the implicit knowledge of the theorems of a classical two-valued semantics, which assigns epistemically transcendent truth conditions to sentences.

Dummett's argument against semantic realism is known as The Manifestation Argument and has the form of a reductio: ${ }^{6}$

1. Knowledge of meaning is knowledge of classical truth conditions.

2. Knowledge of meaning consists in the capacity to recognize, if appropriately placed, whether or not truth conditions obtain.

3. Classical truth conditions are such that, if actualized, they need not be recognizably so.

4. Knowledge of meaning is not knowledge of classical truth conditions.

${ }^{4}$ See Dummett 1975: 99: 'A theory of meaning is a theory of understanding.'

${ }^{5}$ See Dummett 1976: 72: 'We may therefore require that the implicit knowledge which he [the speaker] has of the theorems of the theory of meaning which relate to whole sentences be explained in terms of his ability to employ those sentences in particular ways... The ascription to him of a grasp of the axioms governing the words is a means of representing his derivation of the meaning of each sentence from the meanings of its component words, but his knowledge of the axioms need not be manifested in anything but the employment of the sentence.'

${ }^{6} \mathrm{I}$ borrow this presentation of the manifestation argument from Tennant (1987). 
According to premise 2, every speaker who knows the meaning of a sentence $\mathrm{S}$ must be able to recognize that its classical truth conditions obtain whenever they obtain. But S's classical truth conditions might obtain without being it possible to know that this is so. Therefore, there is no guarantee that the knowledge of S's meaning consists in a capacity that can be ever exercised. This is an absurd consequence, since to have a capacity is to be able to do something that can be done. Nobody possesses a capacity to do anything that cannot be done. Dummett drew the conclusion 4, which is the negation of premise 1, i.e. of semantic realism.

The argument rests on premise 2, which is a consequence of thesis (II). Thesis (II) is known as the manifestation constraint and is Dummett's explication of Wittgenstein's slogan that meaning is use. It expresses the view that the theory of meaning must include the theory of sense, which specifies that in which the knowledge of meaning consists. ${ }^{7}$ Dummett said that a theory that meets the manifestation constraint specifies not only what speakers know, when they know the meanings of the expressions of the language they speak, but also that in which such knowledge consists, in such a way that one would acquire the knowledge of the meanings of the expressions of the language under study, were one taught the practical abilities that the theory of sense is called to describe.

The manifestation constraint has a constitutive import. It regards linguistic behaviour as something in need of analysis. Linguistic behaviour is analysed in order to determine the complex of linguistic abilities that constitute the mastery of the language. To know that a certain expression has a certain meaning is to be able to make a certain use of that expression and the theory of meaning must describe such patterns of use.

Some philosophers have rejected Dummett's Manifestation Argument by rejecting thesis (II), with its constitutive significance. They hold that the ascription of the implicit knowledge of the theory, which for each sentence specifies its classical truth-conditions, amounts to the ascription

\footnotetext{
${ }^{7}$ See, for example, Dummett 1977: 376: 'An argument of this kind is based upon a fundamental principle, which may be stated briefly, in Wittgensteinian terms, as the principle that a grasp of the meaning of an expression must be exhaustively manifested by the use of that expression and hence must constitute implicit knowledge of its contribution to determining the condition for the truth of a sentence in which it occurs; and an ascription of implicit knowledge must always be explainable in terms of what counts as a manifestation of that knowledge, namely the possession of some practical capacity.'
} 
of internal states and allows for testable predictions about speakers' linguistic behaviour. They reject Dummett's manifestation constraint that semantics (theory of reference) - the core part of the theory of meaning - must be associated with a theory of understanding - the theory of sense - that provides an analysis of linguistic behaviour that isolates the patterns of linguistic abilities that constitute the implicit knowledge of the semantic theory. ${ }^{8}$

I will not defend Dummett's theses (I) and (II). I agree that there is a division in the philosophical labour between metaphysicians and philosophers of language, and that the philosophy of language does not have a foundational role in respect of other philosophical fields. I also agree that the Manifestation Argument can be blocked by rejecting the constitutive constraint. However, I will argue that there is a constraint that makes the link between linguistic competence and semantics more intimate than some philosophers believe. I take this constraint to be part of Dummett's legacy in the philosophy of language. I will address the point by discussing Cappelen and Lepore's criticism of Incompleteness Arguments. I will claim that despite the fact that they recognize a division in the philosophical labour between metaphysicians and philosophers of language, their criticism of Incompleteness Arguments is mistakenly grounded on an underestimation of the connection between linguistic competence and semantics. ${ }^{9}$

\footnotetext{
${ }^{8}$ Dummett goes on to argue that classical semantics is not adequate because there are no linguistic abilities that constitute implicit knowledge of epistemically transcendent truth conditions. See Dummett 1991: 303: 'A semantic theory may be criticised on the ground that it cannot be extended to a coherent or workable meaning-theory at all; and since, by definition, a semantic theory can be so extended, this criticism amounts to saying that it is not, after all, a genuine semantic theory.'

${ }^{9}$ It is worth noticing that I will not draw any conclusion against classical bivalent semantics. To the extent that I defend the Incompleteness Arguments against Cappelen and Lepore's criticism, I draw a conclusion against Minimalism in semantics, and in favor of Contextualism. I mention Dummett's view to argue that theoretical reflections on speakers' linguistic competence and linguistic practice put some constraints on semantics and that Minimalism does not satisfy such constraints. In this paper I use 'Minimalism' in the same sense as Cappelen and Lepore (2005: 1) use it. On Cappelen and Lepore's view there are few expressions that are context sensitive, and such expressions belong to the Basic Set of genuinely context sensitive expressions: indexicals ('I'), demonstratives ('that'),
} 


\section{Incompleteness arguments}

Contextualists employ Incompleteness Arguments to maintain that certain expressions are context sensitive. Consider the following sentence:

(1) Bradley is tall.

An Incompleteness Argument starts from the premise that if one takes (1) in isolation from the information available in the context of utterance, then one is unable to truth evaluate (1). It is only if one takes account of contextual information that utterances of (1) are truth evaluable. For example, in the course of a conversation about the physical characteristics of presidential candidates, the utterance of (1) is true if and only if Bradley is $180 \mathrm{~cm}$ tall or over, i.e. tall in respect of the average height of the presidential candidates. Whereas in the course of a conversation about great NBA centers, the utterance of (1) is true if and only if Bradley is $205 \mathrm{~cm}$ tall or over, i.e. tall in respect of the average height of great NBA centers. This line of reasoning leads to the conclusion that there is no invariant proposition, i.e. the proposition that Bradley is tall simpliciter, which utterances of (1) express in all contexts. On the other hand, one has the intuition that there are both the proposition that Bradley is tall as compared with the class of the candidates to the presidency and the proposition that Bradley is tall as compared with the class of great NBA centers, which are the propositions expressed by utterances of (1) with the help of the information available in the context of utterance. In general, then, a successful Incompleteness Argument gives evidence that there is no invariant proposition that a sentence $\mathrm{S}$ expresses in all contexts of utterance. If, in addition, this conclusion

adverbs ('here'), adjectives ('actual') and contextuals ('enemy'). All semantic context sensitivity is grammatically (i.e. syntactically or morphemically) triggered. I use the term 'Contextualism' in a very broad sense which comprehends indexicalism à la Stanley (2007), according to which the Basic Set of genuinely context sensitive expressions is much larger than Cappelen and Lepore think, but all context sensitivity is linguistically triggered (in the logical form if not in the grammatical form) and pragmatism à la Carston (2002), Travis (2008), Recanati (2011), according to which the Basic Set is even larger and not all context sensitivity is linguistically triggered, but a large part of it involves free pragmatic processes. 
is accompanied with the intuition that in each context of utterance $S$ expresses a truth evaluable content relative to the contextual information, then an inference to the best explanation of that intuition leads to the conclusion that $\mathrm{S}$ (some expressions occurring in it) is context sensitive. For example, the intuition that the truth conditions of (1) and the propositions expressed by it vary, when the contexts of utterance vary, is explained within a theory that treats 'tall' as a context sensitive expression.

\section{Cappelen and Lepore's criticism of incompleteness arguments}

Cappelen and Lepore (2005) reject Incompleteness Arguments because, in their view, arguments of that kind aim at establishing a metaphysical conclusion about the existence of entities that might figure as constituents of propositions, like the property of being tall simpliciter, on the basis of psychological data. Psychological data, however, have no bearing on metaphysical issues. Cappelen and Lepore say that typically an incompleteness argument amounts to the following claim:

Consider the alleged proposition that $\mathrm{P}$ that some sentence $\mathrm{S}$ semantically expresses. Intuitively, the world can't just be P simpliciter. The world is neither P nor not P. There's no such thing as P's being the case simpliciter. And so, there is no such proposition.

So, for example, consider 'Al is ready'. Some authors contend that it is just plain obvious that there isn't any such thing as Al's being ready simpliciter. (Cappelen and Lepore 2005: 11)

Their presentation of incompleteness claims has unequivocally a metaphysical import. Cappelen and Lepore argue that those philosophers, who make use of Incompleteness Arguments to support Contextualism, are guilty of conflating metaphysical issues with linguistic ones. The data about speakers' dispositions to truth evaluate sentences in their contexts of utterance might be revelatory about psychological facts and facts about communication, but have no weight for metaphysical inquiries on what entities exist.

I claim that Cappelen and Lepore's criticism of Incompleteness Arguments reveals their misunderstanding of the real nature of such 
arguments and, consequently, their underestimation of the real force of the arguments of that kind. Consider Taylor's illustration of an incompleteness argument. Discussing the structure of the semantic content of utterances of (2):

(2) It is raining.

Taylor says: ${ }^{10}$

[(2)] is missing no syntactic sentential constituent, nonetheless, it is semantically incomplete. The semantic incompleteness is manifest to us as a felt inability to evaluate the truth value of an utterance of [(2)] in the absence of a contextually provided location (or range of locations). This felt need for a contextually provided location has its source, I claim, in our tacit cognition of the syntactically unexpressed argument place of the verb 'to rain'. (Taylor 2001: 61)

Leaving aside Taylor's own view about the semantics of the verb 'to rain', which goes along the lines of the Hidden Indexical Theory, Taylor's idea of incompleteness is that if a sentence gives rise to a felt inability to truth evaluate its utterances independently of contextual information, then the sentence contains some context sensitive expressions. As said above, Cappelen and Lepore's criticism is that an argument such as Taylor's must be rejected because psychological facts about how speakers feel about the truth evaluation of sentences have no weight on metaphysical questions about what entities exist.

\section{The real goal of incompleteness arguments}

I will not raise questions about the truth of Cappelen and Lepore's claim that psychological facts have no bearing on metaphysical questions. I will argue, instead, that the truth of this claim is beside the point, because an incompleteness claim is not a metaphysical claim on the existence of this or that entity. Incompleteness Arguments do

\footnotetext{
${ }^{10}$ The quotation from Taylor serves to highlight the idea that an incompleteness argument starts from a premise that registers the speakers' felt inability to truth evaluate some utterances independently of contextual information. Nothing in the quotation from Taylor gives evidence in favour of Cappelen and Lepore's reading of Incompleteness Arguments according to which a metaphysical conclusion about the existence of certain entities follows from that premise.
} 
not provide evidence against the existence of certain entities, which might figure as constituents of propositions, but against the idea that such entities, if any, can be semantically associated with words as their semantic contents. I hold that an incompleteness claim is a significant claim in respect of linguistic competence and theoretical considerations about linguistic competence do have consequences for semantics (so I will argue). For example, the conclusion of an incompleteness argument concerning the adjective 'tall'"11 is not that the property of being tall simpliciter does not exist, because speakers are unable to truth evaluate the sentence (1) independently of contextual information. One might agree with Cappelen and Lepore that the existence and possibly the account of the property of being tall simpliciter is a matter for metaphysicians not for philosophers of language. I claim that the conclusion of the incompleteness argument is that a semantic theory, which assigned the property of being tall simpliciter to the adjective 'tall' as its semantic value, would be incompatible with any account of linguistic competence, according to which to learn the meaning of an expression and to be competent about its use is to be able to use that expression insofar as that expression is governed by a semantic norm (or by a semantic property with a normative import). Such a semantic theory could hardly have any theoretical interest for an overall theory of language use and linguistic behaviour. I shall elaborate on this point.

Cappelen and Lepore argue that the felt inability to truth evaluate a simple sentence like 'Bradley is tall' offers no positive evidence against the view that the property of being tall simpliciter exists and

${ }^{11}$ It is not the aim of this paper to defend contextualism about this or that expression. If one says to have the intuition that the sentences 'Bradley is tall' and 'the leaves are green' have determinate truth conditions independently of contextual information, that is fine to me with regard to the purpose of this paper and I will not argue to the contrary. The aim of this paper is to defend incompleteness arguments from Cappelen and Lepore's criticism. One might change the examples I discuss with others involving different sentences. Notice that Cappelen and Lepore do not question the premise that speakers are not able to evaluate certain sentences independently of contextual information. Thus, the reader is free to choose one of those sentences. Cappelen and Lepore grant that premise but argue that incompleteness arguments are illegitimate because they conflate premises that register psychological data with metaphysical conclusions. I argue that the conclusions of incompleteness arguments are not metaphysical at all. 
is the semantic content of the adjective 'tall'. On the one hand, Cappelen and Lepore acknowledge that the question of giving an analysis of the property of being tall simpliciter or an account of what makes something tall simpliciter is a difficult problem, but one for metaphysicians, not for semanticists. On the other hand, Cappelen and Lepore (2005: 164) hold that semanticists have no difficulty at all to say which proposition the simple sentence 'Bradley is tall' expresses: it is the proposition that Bradley is tall. Nor have semanticists any difficulty to tell the truth conditions of the simple sentence 'Bradley is tall': 'Bradley is tall' is true if and only if Bradley is tall.

I claim that Cappelen and Lepore's confidence in disquotational truth conditions betrays their underestimation of Incompleteness Arguments. A semantic theory for a language $\mathrm{L}$ aims to capture the semantic properties of the expressions of $\mathrm{L}$. The point, which is relevant to our discussion, is that a semantic theory must be related to linguistic competence. This is so not only for those philosophers who hold that a semantic theory is a theoretical representation of the implicit knowledge of the language, which competent speakers possess. It is so also for those philosophers who reject the view that a semantic theory is a theoretical representation of what competent speakers implicitly know. ${ }^{12}$ Indeed, a semantic theory for L cannot be fully assessed in isolation from questions related to how L-expressions are bestowed with their semantic properties and to what L-speakers typically do, whenever they are regarded as competent in the use of L, especially questions as to whether the linguistic abilities they manifest count as governed by semantic normative principles.

${ }^{12}$ See, for example, Devitt 1981: 93: 'What need explaining, basically, are the verbal parts of human behaviour. In explaining these, we must attribute certain properties (for example, being true and referring to Socrates) to the sounds and inscriptions produced, and certain other properties (for example, understanding "Socrates") to the people who produce those sounds and inscriptions.' See also Devitt 1999: 169: 'Linguistic competence is a mental state of a person, posited to explain his linguistic behaviour; it plays a key role_-although not, of course, the only role - in the production of that behaviour. Linguistic symbols are the result of that behaviour; they are the products of the competence, its outputs... A theory of a part of the production of linguistic symbols is not a theory of the products, the symbols themselves. Of course, given the causal relation between competence and symbols we can expect a theory of the one to bear on a theory of the other. But that does not make the two theories identical.' 
Suppose a semantic theory for, say, English contains a disquotational principle like the following, which arguably captures what Cappelen and Lepore have in mind, when they say that the semantic content of 'tall' is the property of being tall simpliciter and that semanticists have not difficulty at all to tell the truth conditions of 'Bradley is tall' and which proposition it expresses:

(A) For any object $o$, 'tall' applies in English to $o$ if and only if $o$ is tall.

The point I want to stress is that it is theoretically significant for that semantic theory that an account is available about how the linguistic abilities of competent speakers count as governed by the principle (A). It is also theoretically significant that an account is available about how it comes that the word 'tall' has the semantic property of applying to all and only tall simpliciter objects. If there is evidence that no account of that kind is available, then there is evidence that the semantic theory in question is on a wrong track. As Michael Devitt (2007: 52) says, semantic contents are not "God given", but as conventions need to be established and sustained by regular uses. Words cannot have the semantic contents they have independently of the linguistic behaviour of competent speakers. Otherwise, it is impossible to explain how words get associated with their semantic properties and how such associations are learned (and transmitted) by being exposed to the linguistic practice. Moreover, a semantic theory that does not enable us to describe the linguistic behaviour as subject to semantic principles with a normative import is scarcely of any interest for an overall account of language use.

I claim that the gist of Incompleteness Arguments is not that certain entities, such as the property of being tall simpliciter, do not exist. Rather, it is that such entities, if any, cannot be the semantic contents of words. A semantic theory that assigned such entities to words, as their semantic contents, would be incompatible with any plausible account of language learning and language understanding, according to which by learning and understanding a language, we learn and understand expressions as governed by semantic principles with normative import.

Consider one of Travis' (1997) favourite examples. A speaker utters the sentence (3): 
(3) The leaves are green.

speaking of a Japanese maple, whose leaves are naturally russet but have been repainted green. In a context of utterance in which the speaker talks with a photographer, who looks for a green subject, the speaker is taken to tell the truth. In another context of utterance in which the speaker talks with a botanist, who is interested in the natural colour of the plant, the speaker is not taken to tell the truth. The point that an incompleteness argument brings out is that competent speakers feel unable to truth evaluate utterances of the sentence (3) independently of the information available in the context of utterance. This result means that the linguistic abilities that are required for the mastery of the word 'green' cannot be construed as governed by the semantic norm expressed by the following disquotational principle:

(B) For any object $o$, 'green' applies in English to $o$ if and only if $o$ is green.

The reason why linguistic competence cannot be so construed is that the linguistic practice cannot be guided by such principle. As a matter of fact, the principle (B) states conditions of the application for 'green' that competent speakers are never able to track, as testified by their felt inability to truth evaluate sentences such as (3) independently of contextual information. To put it another way, the principle (B) specifies the semantic content of the word 'green'. Hence, the principle (B) states a norm about the use of 'green': it is correct to apply 'green' to all and only green simpliciter objects. Incompleteness Arguments show that the norm that the principle (B) states is not applicable, because nobody in the linguistic community is able to tell when it applies and when it does not. Since norms must be applicable, the conclusion follows that the principle (B) states no norms at all and, therefore, cannot be a semantic principle. The principle (B) does not play the normative role that is constitutive of semantic principles.

The consequence of Cappelen and Lepore's view is more radical and damaging than the view held by externalists such as Putnam (1975). Externalists hold that semantic properties are objective in the sense that words have their semantic properties independently 
of explicit knowledge and discriminating abilities, which speakers or the linguistic community as a whole possess. In 1750, 'water' in Twin Earthian English referred to XYZ even though nobody knew the chemical composition of the liquid stuff on Twin Earth and nobody could discriminate $\mathrm{XYZ}$ from $\mathrm{H}_{2} \mathrm{O}$. Externalism has the consequence that semantic norms might elude even the most expert speakers of the community. In 1750, nobody could have been in a position to correct an application of the Twin Earthian word 'water' to $\mathrm{H}_{2} \mathrm{O}$. Had a Twin Earthian speaker talked to an Earthian speaker, they would have misunderstood each other, one speaking of XYZ and the other of $\mathrm{H}_{2} \mathrm{O}$. As Marconi (1997: 88) remarks, that would be a misunderstanding of a very peculiar kind, since nobody in the linguistic community could have pointed it out.

It is not my interest here to take side with externalists and defend their view from Marconi's criticism. Rather, my interest is to highlight the difference between externalism and the radical position that issues from Cappelen and Lepore's view. Externalists hold that semantic properties are unaffected by explicit knowledge and discriminating abilities. Semantic properties are determined by certain factual, causal connections to the world. Externalists, however, do have an account of how words are bestowed with their semantic properties, which rests on baptismal ceremonies and, above all, multiple groundings. A word has the reference it has because most significant referential practices, as a matter of fact, are related to that reference. This means that there are favourable-contextually favourable, not epistemically or cognitively favourable - circumstances in which Twin Earthian competent speakers believe, and believe it truly, that the conditions for the application of 'water' are satisfied. This confers the following principle:

(C) 'water' refers in Twin Earthian English to XYZ.

its normative role, although it might elude even the most expert speakers in the whole community, when they are not in a contextual favourable position (say an expert Twin Earthian speaker has been transported to Earth). Therefore, there are favourable circumstances in which Twin Earthian competent speakers are disposed to truly assent to the sentence 'that is water' and to correctly truth evaluate other sentences containing the word 'water'. 
Incompleteness Arguments show that competent speakers are never disposed to truth evaluate sentences containing certain words independently of contextual information. For example, there are no circumstances in which competent speakers are disposed to truth evaluate 'Bradley is tall' independently of contextual information. This means that competent speakers are never able to track instances of the property of being tall simpliciter. This fact prevents any semantic theory from ascribing the property of being tall simpliciter to the adjective 'tall' as its semantic content by means of the principle (A), because competent speakers are never able to tell when the conditions for the application of 'tall', as captured by the principle (A), are satisfied. Such semantics is not compatible with any account of how the adjective 'tall' is bestowed with its semantic property and of how such semantic property exerts a normative role over the linguistic practice.

\section{Cappelen and Lepore's charge of verificationism}

Cappelen and Lepore (2005: 164-5) take into consideration this form of resistance to their rejection of Incompleteness Arguments. They respond that semantics is not in the business of telling what the world is like. Therefore, semantics is not in the business of telling whether, say, the utterance of the sentence 'Uma Thurman has red eyes' is true or not. The fact that a semantic theory for a language $\mathrm{L}$ does not instruct $\mathrm{L}$-speakers to ascertain the truth value of L-sentences is not a defect of the semantic theory. Cappelen and Lepore remind us that it is trivial that a proposition with a determinate truth value is expressed by a felicitous utterance of the sentence ' 100,000 years ago an insect moved over this spot', although we have no idea whether it is true or not and no idea how to find out whether it is true or not. Thinking otherwise, they say, would be to indulge in verificationism.

I find Cappelen and Lepore's response mistaken. The accusation of verificationism misses the target of our discussion. I agree that theorists, who do not adhere to verificationism, do not identify the knowledge of the proposition expressed by the utterance of a sentence with the knowledge of a method for its verification. Theorists, who are not verificationists, agree that competent speakers fully understand the proposition expressed by the utterance of the sentence 
'100,000 years ago an insect moved over this spot' without being in a position to verify whether it is true or not. On the other hand, also theorists who are not verificationists cannot ignore questions as to how that sentence got the content it has and what linguistic abilities distinguish people who understand it from people who do not. Notice that I am not claiming that it is a task for semantics to find out answers to those questions. My claim is that a semantic theory must be compatible with an account that provides such answers.

A theorist, who is not a verificationist nor a semantic antirealist and takes the sentence '100,000 years ago an insect moved over this spot' to depict an epistemically inaccessible state of affairs, will not hold that the understanding of such sentence is manifested by the capacity to tell whether its truth conditions are satisfied or not. Nor can the understanding of the sentence ' 100,000 years ago an insect moved over this spot' be traced back to the ability to explicitly formulate the disquotational truth-condition '100,000 years ago an insect moved over this spot' is true if and only if 100,000 years ago an insect moved over this spot (over the demonstrated spot), for the simple reason that many competent speakers are not able to do so. One option left is to say that a criterion for understanding is that one understands the sentence '100,000 years ago an insect moved over this spot' only if one understands the single expressions that form the sentence and the syntactic structure of the sentence. The question arises as to how the understanding of the single expressions is manifested.

It has been argued ${ }^{13}$ that linguistic competence has two components, one inferential and the other referential. The inferential component consists in the ability to manage a network of connections among words. For example, we recognize as competent speakers those people who manifest the disposition to make the inference from, say, 'A is an insect' to 'A is an animal', or are able to give a definition of 'insect', or are able to find a synonym for 'insect', or are able to retrieve the word 'insect' from its definition, etc. The referential component consists in the ability to map words to the world. For example, the disposition to give the assent to the sentence 'that is an insect' in presence of an insect or the ability to correctly obey an order such as 'point at an insect'. This account of linguistic

${ }^{13}$ See Marconi 1997. 
competence together with the assumption, arguably shared, that the competence in the use of the expression 'insect' requires both referential and inferential abilities demands that the following principle:

(D) For any object $o$, 'insect' applies in English to $o$ if and only if $o$ is an insect.

assign the expression 'insect' a kind as its semantic content such that there must be circumstances, at least in favourable contextual conditions, in which competent speakers believe - and believe it trulythat it is instantiated. Otherwise, no matter what the linguistic competence in the use of the word 'insect' turns out to be, it is detached from the normative role of the principle (D). The result is that one gets a semantics that is useless for an overall theory of language use, since it prevents us from accounting for the linguistic practice as governed by semantic principles with normative roles.

This is the constraint that a theory of linguistic competence poses on semantics: the linguistic practice in the use of a language L needs to be taken as the manifestation of the understanding of L-expressions as governed by semantic principles with normative roles. The point of Incompleteness Arguments is that a semantic theory, which employs principles such as (A) and (B), violates such constraint. Incompleteness Arguments start with the premise that speakers are never able to believe that the property of being tall simpliciter or the property of being green simpliciter are instantiated, i.e. that the conditions for the correct application of 'tall' and 'green', as captured by the principles (A) and (B), are satisfied, because competent speakers have no beliefs about the truth value of simple sentences like 'Bradley is tall' or 'the leaves are green' independently of contextual information. Hence, the linguistic practice of competent speakers shows that their understanding of 'tall' and 'green' is not governed by the principles (A) and (B).

Analogous considerations show that learning the mastery of 'tall' and 'green' cannot amount to learning the meaning of words as governed by the principles (A) and (B). Arguably, we pick up the meaning of expressions, like 'tall' and 'green', by being exposed to assertions of simple sentences, like 'Bradley is tall' and 'the leaves are green'. Incompleteness Arguments show that assertions of simple sentences, such as 'Bradley is tall' and 'the leaves are green', cannot 
be the expression of the belief that Bradley is tall simpliciter and the leaves are green simpliciter, i.e. the belief that the conditions for the application of 'tall' and 'green', as captured by the principles (A) and (B), to Bradley and to the leaves are satisfied. As a matter of fact, competent speakers have no beliefs about the truth value of those sentences independently of contextual information. If the assertions of simple sentences like 'Bradley is tall' and 'the leaves are green' are not the expression of the belief that the conditions for the application of 'tall' and 'green', as captured by the principles (A) and (B), to Bradley and to the leaves are satisfied, whatever one learns through the exposure to assertions of that kind is not a mastery of words as governed by semantic norms expressed by the principles (A) and (B).

\section{Two final clarifications}

The premise of an incompleteness argument registers the fact that if speakers do not take into account the contextual information, they have no beliefs about the truth value of sentences such as 'the leaves are green'. I argued that an incompleteness argument moves from that premise to the conclusion that the property of being green simpliciter, if any, cannot be the semantic content of the adjective 'green'. The point is semantic, not metaphysical. If speakers do not have any beliefs about when the property of being green simpliciter applies to objects, then they do not have any beliefs about when the conditions for the application of 'green', as captured by the axiom (B), are satisfied. This fact makes such axiom normatively idle.

One might raise the following objection. It might well be that speakers have beliefs about the truth value of sentences such as 'the leaves are green' only if they take into account the contextual information. However, this does not entail that the adjective 'green' has no invariant semantic content, i.e. a semantic content that is independent of context. One might say that whenever a speaker believes that the sentence 'the leaves are green' is true taking into account the contextual information, the speaker ipso facto believes that the condition for being green simpliciter are satisfied, and thereby the speaker believes that the condition for the application of 'green', as captured by the axiom (B), are satisfied.

An objection like this one is the obvious consequence of combining 
the minimalist view in semantics with a modest metaphysical account of the property of being green simpliciter. The axiom (B)

(B) For any object $o$, 'green' applies in English to $o$ if and only if $o$ is green (simpliciter)

is combined with the following modest account of what it takes to be green simpliciter:

For any object $o, o$ is green simpliciter if and only if $o$ looks green on some surface under some circumstances.

Cappelen and Lepore do not explicitly defend such metaphysical view. They coherently refuse to be committed to it because a defense of any metaphysical theory is homework for metaphysicians and not for philosophers of language. However, they confess their sympathy to it when they respond to the following objection. Let us assume that 'the leaves are green' is true if and only if the leaves are green on some surface under some circumstances. Doesn't that make it very, indeed, too easy to be green? Doesn't that make, say, the White House green? Cappelen and Lepore respond that when we think hard about what it is to be green, maybe that is all it takes to be green. If so, then it would turn out that it is not so hard to be green. Cappelen and Lepore say that whether one finds this picture congenial or not it is not a problem that arises because of views one might hold about the context sensitivity of 'green'.

Thus, Cappelen and Lepore's response is that the above objection confuses a metaphysical issue with a semantic one. My counter-reply is that the above objection has a semantic reading. If what it takes to be green simpliciter is to look green on some surface under some circumstances, then any object $o$ is green simpliciter. It follows that any sentence of the form ' $\mathrm{O}$ is green' is trivially true (granted the existence of $\mathrm{O}$ ). Now, this picture is not in line with the normativity of semantic principles. An axiom such as (B) turns out to state conditions for the application of 'green' that are always trivially satisfied, because it is trivially true that anything looks green on some surface under some circumstances. This contrasts with the idea that when we learn the meaning of 'green' we learn a rule that tells us the circumstances in which it is correct to apply it apart from the circumstances in which it is not. Indeed, a consequence of semantic 
minimalism combined with the above modest metaphysical view is not only that it is a trivial truth that any object is green, but also that it is a trivial truth that any object is green and red and blue and so forth for any color. In conclusion, this picture, which combines semantic minimalism with the modest metaphysical view, deprives the axiom (B) of its normative import, and I argued that this is a flaw in the field of semantics, not in the field of metaphysics.

The very same problem about normativity does not affect Contextualism in semantics, or at least some of its versions. Suppose a contextualist theory says that 'green' is a context dependent expression and its meaning is given by the rule that 'green' must be applied to an object with respect to some contextually relevant surface under some contextually relevant circumstances. Of course, selected a surface and certain circumstances in a context, it is correct to apply 'green' to an object if and only if that object looks green on that surface under those circumstances. It is not a trivial truth that an object is green in this sense. For example, it is not a trivial truth that the leaves of the Japanese maple in the photographer's studio have been painted green.

I dedicate a final reflection on the argument for the existence of invariant contents that says that although they do not fit speakers' intuitive judgments about the truth conditional content of assertions in contexts, they nevertheless play an indispensable role in communication and, contrary to what some contextualists hold, they are psychologically real.

Cappelen and Lepore maintain that invariant semantic contents play a function in the cognitive life of communicators that no other content can play. ${ }^{14}$ The idea is that invariant contents have a role to play as fallback content, i.e. the content which is guaranteed to be recoverable in a communicative exchange when something goes wrong due to the fact that either the speaker or the hearer or both have an imperfect, partial, limited, erroneous grasp of the contextual information. The invariant content is that content the speaker (the audience) can expect the audience (the speaker) to grasp (and expect the audience (the speaker) to expect the speaker (the audience) to expect them to grasp) even if they have mistaken or incomplete contextual

${ }^{14}$ See also Borg 2007, 2009 and 2012. 
information. Cappelen and Lepore say that the invariant content is our defense against confusion, misunderstanding and mistakes. Even if the invariant content is trivially true, as in the case of an object being green on some surface under some circumstances, nonetheless it is a starting point from which the content that the speaker intended to communicate can be recovered. Therefore, the invariant contents are psychologically real.

My reply is that this argument is a non sequitur. The conclusion that certain expressions are not context dependent and have an invariant semantic content does not follow from the premise that invariant contents play an important role in communication. Consider the expression 'I'. Nobody will put in question that 'I' is a context dependent expression. 'I' is an indexical which Cappelen and Lepore put into the basic set of context dependent expressions. Suppose one overhears the utterance of the sentence 'I have headache' coming from the next room without having access to the contextual information, i.e. without knowing who is the speaker of the utterance. This is a case in which something goes wrong due to the fact that one has an imperfect grasp of the contextual information. Nonetheless, there is a content that one can understand in virtue of being a competent speaker. One understands that the speaker of that utterance has headache. That there is a unique speaker of that utterance who suffers from headache is a content that one can grasp even if one does not know who is the speaker, and therefore one cannot grasp what the speaker said, i.e. the semantic content of that utterance. The recovered content might play an important role. One can enter the next room and ask who uttered the sentence 'I have headache' in order to discover who is the speaker, and hence in order to understand the content that the speaker semantically expressed. Although there is an invariant content that one can grasp in virtue of being a competent speaker, it does not follow that the expression 'I' is not context dependent. In general, as far as indexicals and demonstratives are concerned, competent speakers can recover invariant contents from their characters, and such contents can play an important role in communication. Of course, it does not follow that indexicals and demonstratives are not context dependent expressions.

Consider now a contextualist theory that says that 'green' is a context dependent expression with the rule that 'green' applies to 
an object with respect to a contextually relevant surface under some contextually relevant circumstances. Suppose one overhears an utterance of the sentence 'that is green' coming from the photographer's studio without having access to the studio. In virtue of being a competent speaker, one knows that what the speaker said is true if and only if there is a contextually relevant object that has a contextually relevant surface looking green under some contextually relevant circumstances. This is not what the speaker said. The speaker semantically expressed the proposition that that Japanese maple has the leaves repainted green. Although one cannot grasp such proposition, which is the semantic content of the assertion, the recovered content one understands is a starting point that might lead to grasp the semantic content.

Thus, my conclusion is that no doubt there are invariant contents that can be associated with certain expressions in virtue of being recoverable from our knowledge of their meaning. No doubt such contents are psychologically real and might play important roles in communication. However, it does not follow that those expressions are not context dependent.

\section{Conclusions}

I argued that the conclusions of Incompleteness Arguments are not that certain entities do not exist. Those are metaphysical questions that metaphysicians are called to answer. Contrary to Cappelen and Lepore's view, and no matter what metaphysicians are willing to say, Incompleteness Arguments show that even if one acknowledges the existence of certain entities, e.g. the property of being tall simpliciter and the property of being green simpliciter, such entities cannot be the contents that a semantic theory associates with words, because a semantic theory so construed is incompatible with theoretical considerations about language learning and language understanding.

One can agree with Cappelen and Lepore on keeping issues in metaphysics apart from issues in the philosophy of language and on rejecting Dummett's thesis (I). One can also agree with Cappelen and Lepore on rejecting Dummett's thesis (II) and its constitutive constraint that the linguistic competence must constitute the implicit knowledge of semantics, which, in Dummett's view, is the premise 
that leads to semantic antirealism. However, one cannot go too far, as Cappelen and Lepore go, in detaching semantics from linguistic competence. There is a constraint that a theory of linguistic competence poses on semantics: the linguistic practice needs to be taken as the manifestation of the understanding of words and as the basis for the learning of their meaning insofar as they are words governed by semantic principles with normative import. If certain semantic principles are not suitable for such an account of linguistic competence, then any semantic theory that endorses them is on the wrong track. I take this result, which points at an intimate connection between linguistic competence and semantics, to be an important part of Dummett's legacy in the philosophy of language.

Massimiliano Vignolo Dept. of Philosophy University of Genoa 16124 Genoa, Italy maxi@nous.unige.it

\section{References}

Borg, Emma. 2007. Minimalism versus Contextualism in Semantics. In ContextSensitivity and Semantic Minimalism, ed. by G. Preyer and G. Peter. Oxford: Oxford University Press, 339-359.

Borg, Emma. 2009. Minimal Semantics and the Nature of Psychological Evidence. In New Waves in Philosophy of Language, ed. by S. Sawyer. Basingstoke: Palgrave Macmillan, 24-40.

Borg, Emma. 2012. Semantics without Pragmatics. In The Cambridge Handbook of Pragmatics, ed. by K. Allen and K. Jaszczolt. Cambridge: Cambridge University Press, 513-528.

Cappelen, Herman and Lepore, Ernest. 2005. Insensitive Semantics. A Defense of Semantic Minimalism and Speech Act Pluralism, Oxford: Blackwell.

Carston, Robyn. 2002. Thoughts and Utterances: The Pragmatics of Explicit Communication. Oxford: Blackwell.

Devitt, Michael. 1981. Designation. New York: Columbia University Press.

Devitt, Michael. 2007. Referential Descriptions: a Note on Back. European Journal of Analytic Philosophy 3: 49-53.

Devitt, Michael and Sterelny, Kim. 1999. Language and Reality, 2nd edition. Oxford: Clarendon Press.

Dummett, Michael. 1975. What is a Theory of Meaning? In Mind and Language, ed. by S. D. Guttenplan. Oxford: Oxford University Press, 95-138. 
Dummett, Michael. 1976. What is a Theory of Meaning? (II) In Truth and Meaning, ed. by G. Evans and J. McDowell. Oxford: Clarendon Press, 67-137.

Dummett, Michael. 1977. Elements of Intuitionism. Oxford: Clarendon Press. Dummett, Michael. 1978. Truth and Other Enigmas. London: Duckworth. Dummett, Michael. 1981. Frege, Philosophy of Language, 2nd edition. London: Duckworth.

Dummett, Michael. 1991. The Logical Basis of Metaphysics. London: Duckworth. Marconi, Diego. 1997. Lexical Competence. Cambridge MA: MIT Press.

Putnam, Hilary. 1975. The Meaning of 'Meaning'. In Philosophical Papers vol. 2, Mind Language and Reality, Cambridge MA: Cambridge University Press, 215-271.

Recanati. Francois. 2011. Truth-Conditional Pragmatics. Oxford: Clarendon Press. Stanley, Jason. 2007. Language in Context. Oxford: Oxford University Press.

Taylor, Kennet. 2001. Sex, Breakfast, and Descriptus Interruptus. Synthese 128: 45-61.

Tennant, Neil. 1987. Antirealism and Logic. Oxford: Clarendon Press.

Travis, Charles. 1997. Pragmatics. In A Companion to the Philosophy of Language, ed. by B. Hale and C. Wright. Oxford: Blackwell, 87-107.

Travis, Charles. 2008. Occasion-Sensitivity. Oxford: Oxford University Press.

Wright, Crispin. 1983. Frege's Conception of Numbers as Objects. Aberdeen: Aberdeen University Press. 